\title{
Development and validation of an Arabic questionnaire to assess psychosocial determinants of eating behavior among adolescents: a cross-sectional study
}

\author{
Leila Itani ${ }^{1,2^{*}}$ (D), Hanadi Chatila ${ }^{3}$, Hani Dimassi ${ }^{4}$ and Fikrat El Sahn ${ }^{5}$
}

\begin{abstract}
Background: There is a scarcity of studies that evaluate the psychosocial determinants of eating behavior among adolescents in the Eastern Mediterranean region. The availability of such data is limited by the lack of valid culturally appropriate tools. The current study aims to develop and validate an Arabic questionnaire that measures psychosocial determinants of eating behavior among adolescents.

Methods: A cross-sectional study was carried out to validate a five-scale questionnaire developed to measure nutrition-related knowledge, attitude, practices, and self-efficacy and social norms. Content validity was assessed by Lawshe's method, factor analysis was used to assess construct validity, and Cronbach's a was used to test internal consistency. Temporal stability was assessed by test-retest reliability. A random sample of public and private school students participated in the validation study.

Results: All the five scales demonstrated excellent content validity (content validity ratio, CVR $\geq 0.778$ ). Factor analysis revealed several dimensions for each scale. Cronbach's a for the identified dimensions or subscales ranged between 0.495 and 0.809 indicating acceptable internal consistency. Cronbach's a for the total scales ranged between 0.759 and 0.836. Test-retest analysis revealed good temporal stability (intraclass correlation, ICC $>0.7$ ).

Conclusions: A psychometrically valid tool to measure psychosocial determinants of eating behavior was developed. This tool can serve as a potential instrument for pretest and impact evaluation of ongoing nutrition education interventions and curricula. Based on results obtained from this tool, efficacious modifications can be instilled for nutrition policies and interventions.
\end{abstract}

Keywords: Questionnaire, Psychosocial determinants, Knowledge, Attitude, Practices, Social norms, Self-efficacy

\section{Background}

Childhood and adolescence are critical periods of life during which eating behavior and food preferences are established and often persist into adulthood [1-4]. However, children cannot adopt a healthy eating pattern by instinct. They need to be informed and motivated through theory-based nutrition education curricula that target psychosocial determinants of eating behavior,

\footnotetext{
*Correspondence: I.tani@bau.edu.lb

${ }^{1}$ Faculty of Health Sciences, Department of Nutrition and Dietetics, Beirut Arab University, Riad El-Solh, Beirut 1107 2809, Lebanon

${ }^{2}$ Doctoral School of Literature, Humanities and Social Sciences, Lebanese University, Sin El Fil, Beirut, Lebanon

Full list of author information is available at the end of the article
}

namely knowledge, attitudes, normative beliefs, and selfefficacy $[5,6]$. The importance of these determinants in shaping nutrition behavior have been recently demonstrated by a significant body of evidence [7-16]. Furthermore, when these determinants are targeted through successful school-based nutrition education interventions, significant changes in nutrition behavior are achieved [13] alongside positive health-related consequences [16].

To promote nutritional health, educators and stakeholders globally issued the "Nutrition-Friendly Schools Initiative" that call on integration of nutrition education into school curricula [17]. Subsequently, the "Regional 
Strategy on Nutrition 2010-2019" was issued for the Eastern Mediterranean region to reduce nutrition problems in the region through intervention strategies including school-based nutrition education [18]. Although many countries in the Eastern Mediterranean region have responded to the strategy, there is a scarcity of studies that evaluate the impact of nutrition education in these countries [19] particularly in terms of psychosocial determinants of eating behavior. Moreover, considering the results of dietary studies in the region, apparently education interventions have been ineffective. These studies revealed unhealthy eating patterns particularly among adolescents [19-25]. The identified patterns included skipping breakfast, westernized patterns, decreased fruit and vegetable intake, and increased sweetened beverage intake. Furthermore, these patterns were associated with health risks including overweight and obesity, enlarged waist, deficiencies, and nutrition-related diseases [19, 20, 26-28]. While dietary patterns and their socioeconomic determinants have been described particularly among adolescents [23, 26, 27, 29], data is still lacking on the psychosocial determinants of these patterns specifically in this age group.

Obviously there is shortage of data on psychosocial determinants of eating behavior among adolescents in the region. Furthermore, the role of these psychosocial determinants in defining nutrition behavior or the nutritional status of adolescents in these countries is not well understood, which hinders its use for designing effective education interventions. The availability of such data is limited by the lack of specific culturally appropriate tools that can measure and evaluate these determinants.

This study attempts to develop and determine the reliability and validity of a self-administered questionnaire that shall serve as a valid evaluation tool for assessing psychosocial determinates of eating behavior among Arabic-speaking adolescents. The results from these evaluations will serve as reference data for future evaluations and reformation toward more effective nutrition education curricula and interventions.

\section{Methods}

\section{Study design}

A cross-sectional study was conducted to determine the validity and reliability of the developed questionnaire.

\section{Questionnaire construction}

The questionnaire development and validation was carried out through the following steps:

\section{Step 1: construction of the questionnaire items}

A literature review of existing questionnaires and dietary guidelines [30-32] was conducted to guide item development. The developed questionnaire consisted of five scales: (1) knowledge, (2) attitude, (3) social norms, (4) self-efficacy, and (5) practices. All food items used in the questionnaire were locally consumed food items. The questionnaire was initially constructed in the English language and then translated to Arabic by the PI to ensure cultural appropriateness. To confirm accurate translation to Arabic, the questionnaire was back translated to English by a translator and the two versions were compared for equivalence. The questionnaire was pilot tested on a group of Lebanese adolescents $(n=6)$, and modifications were introduced accordingly.

\section{Step 2: content validity}

To establish content validity for the final draft, Lawshe's method for content validity analysis was used [33]. The questionnaire items were evaluated by a group of nine dietitians as subject matter experts (SME). The validators rated items either as "essential," "useful," or "not necessary." A dichotomy was then created from the three-point rating scale into "essential," "useful," and "not necessary" (personal communication in an email to Professor F. Robert Wilson (wilsonfrobert@gmail.com), 25 February 2014). A content validity ratio (CVR) for each item was calculated as described by Lawshe [33]. The revised binomial probability distribution for Lawshe's critical values were used to exclude items rated as "not necessary" [34]. Consequently, all those items with CVR below the critical value of 0.778 were excluded [34]. A scale content validity index (S-CVI) was calculated for each scale by averaging the CVR for all the retained items in the scale $[35,36]$. A S-CVI $\geq 0.9$ would indicate excellent content validity at the level of the scale [35].

After modification, 93 items were retained for all the five scales (Table 1).

\section{Step 3: internal consistency and construct validity}

To examine the construct validity and internal consistency of the final questionnaire, a random sample of 482 grade 12 students (17-18 years) from nine public schools in Beirut was selected to participate in the study. Only 159 completed the questionnaire. The time needed to complete the questionnaire was 30-40 $\mathrm{min}$.

Construct validity was determined by exploratory factor analysis with varimax rotation. The Kaiser-MeyerOlkin (KMO) test and the $X^{2}$ Bartlett test of sphericity were used to examine the sampling adequacy and the strength of correlations between each scale item respectively [37]. The number of factors retained was based on the inflection point of the scree plot and the interpretability of factors.

Cronbach's $\alpha$ and item-to-total correlation was used to measure internal consistency of the scales and how 
Table 1 The number of items and sub-items and the maximum and minimum possible score in each scale of the questionnaire

\begin{tabular}{llll}
\hline \multirow{2}{*}{ Scale } & \multirow{2}{*}{$\begin{array}{l}\text { Number of } \\
\text { items }\end{array}$} & Minimum & Maximum \\
\cline { 4 - 4 } Knowledge & 36 & 0 & 127 \\
Attitude & 16 & 16 & 112 \\
Social norms (normative beliefs) & 5 & 5 & 35 \\
Self-efficacy (control beliefs) & 17 & 17 & 51 \\
Practices & 19 & 19 & 95 \\
Total & 93 & & \\
\hline
\end{tabular}

much the items in each scale are interrelated respectively [38, 39]. Cronbach's $\alpha$ was calculated for total scales, for total subscales, and if an item was removed from a subscale. A good consistency of the scale was defined for Cronbach's $\alpha$ values between 0.5 and 0.7 based on dimensionality of the scale [40,41]. However, a lower Cronbach's $\alpha$ was considered sufficient to indicate consistency for scales with less than 10 items [42]. For item-to-total correlation, a correlation higher than 0.2 suggested that each item has a good correlation with the scale [43]. Items having item-to-total correlation less than 0.2 were retained if Cronbach's $\alpha$ did not increase upon deleting these items [44].

\section{Step 4: test-retest reliability of the final questionnaire}

To assess the ability of the questionnaire to measure knowledge, attitude, practices, social norms, and selfefficacy with stability over time, it was administered to a sample of 30 grade 12 students (16 boys and 14 girls) aged 17-18 years, selected randomly from a private and a public school in Beirut. The questionnaire was administered twice with a period of 2 weeks between each sitting. To determine test-retest reliability, a paired $t$ test analysis was conducted to compare mean scores at T1 and T2. Pearson correlation coefficient between test scores at T1 and T2 was calculated and a two-way random effect model with consistency intraclass correlation (ICC) was computed [45]. Values of ICC were interpreted as follows: $>0.75$ was excellent, between 0.40 and 0.75 was fair to good, and $<0.40$ was poor [46].

\section{Scoring of the final questionnaire}

Each scale was scored based on the type of items included. For the knowledge section, questions with single response were coded into 0 and 1 for wrong/do not know and correct answers respectively. The diet-disease-association questions consisted of a composite score for each item (yes/no and specify). The yes and no responses for these questions were coded into 0 and 1 respectively. The "specify" items in this section entailed more than one possible answer; thus, the guessing correction factor suggested by Sočan was applied here [47]. Hence, a correct response was scored with 1 point, a missing item with 0 , and an incorrect response with $-1 /(m-1)$ points, where $m$ is the number of alternative responses. So +1 was given for a correct answer and -1 , $-0.5,-0.33$, or -0.25 for wrong answers depending on the number of response options $(2,3,4$, or 5 respectively) [47]. The same guessing correction scoring factors were applied for vitamin/mineral food sources in the knowledge section since these entailed more than one response. Positive attitude and practices items, social norms, and self-efficacy were not recoded, and the responses for each item ranged between 1 and 7. Responses for negative attitude and practices items were recoded inversely on the Likert scale. The scores for each scale or subscale were calculated by summing up the scores for all the scale items and sub-items. The minimum and maximum scores for each scale are shown in Table 1.

\section{Data analysis}

All data were entered, cleaned, and analyzed using SPSS 21 (SPSS Inc., Chicago, IL, USA). Statistical significance was accepted at $p<0.05$.

\section{Results}

A five-scale questionnaire was developed and validated and assessed for temporal stability.

\section{Content validity}

The content validity ratio (CVR) for each item was either 0.778 or 1 , which is in agreement with the critical value set for considering items as content valid [34]. These results indicate that 88.9 to $100 \%$ of the validators considered the items as either "essential" or "useful." The scale content validity index (S-CVI) was 0.988 for the total knowledge scale, 0.958 for the attitude scale, 1 for the social norms scale, 0.977 for the practices scale, and 0.934 for the self-efficacy scale.

\section{Construct validity}

When the responses for the 159 completed questionnaires were analyzed for construct validity by factor analysis, the Kaiser-Meyer-Olkin measures of sampling adequacy (KMO) ranged between 0.805 and 0.907 for the knowledge, attitude, self-efficacy, and practices scales and it was 0.605 for the social norms scale, indicating that the correlations among the items of each scale was sufficiently strong for a factor analysis [37]. Bartlett's test for sphericity also demonstrated suitability of the data for factor analysis in all the scales $(p<0.001)$. Factor analysis revealed a four-factor solution for the knowledge scale, two factors for the attitude scale, one for the social norms scale, four for the self-efficacy scale, and 
three for the practices scale. The four subscales for the knowledge scale included (1) macronutrients and diseases association, (2) healthy nutrient sources, (3) energy and nutrient balance, and (4) nutritional deficiencies. For the attitude scale, the two subscales were (1) adherence to dietary guidelines and adequacy and (2) salt, sugar, refined grains, and health. For the self-efficacy scale, the four subscales were (1) lifestyle, (2) healthy snacks, (3) calorie control, and (4) adherence to dietary guidelines. For the practices scales, the three subscales were (1) adherence to dietary guidelines, (2) salt and sugar food choices, and (3) lifestyle and portion size. The factor solutions explained 37.12, 41.05, 57.33, 51.32, and $41.42 \%$ of the total variance in each of the knowledge, attitude, social norms, self-efficacy, and practices scales respectively. The factor loadings after varimax rotation for all the scales under study are shown in the Additional file 1. Few items with lower loadings were retained because these items were important for content validity of the scale [37].

\section{Internal consistency}

Item analysis of the five scales under study (knowledge, attitudes, social norms, self-efficacy, and practices) revealed acceptable internal consistency measured by Cronbach's $\alpha$ and item-to-total correlation. Cronbach's $\alpha$ for total scale varied between 0.836 and 0.759 for each of the knowledge, attitude, practices, and self-efficacy scales. Cronbach's $\alpha$ for the four knowledge subscales varied between 0.503 and 0.752 ; for the two attitude subscales, values were 0.495 and 0.809 ; for the four selfefficacy subscales, values varied between 0.595 and 0.727; and for the practices subscales, values varied between 0.475 and 0.756 . Although few subscales attained low Cronbach's $\alpha$, items were retained for the sake of content validity and since these subscales included a small number of items [42]. As for the social norms scale, it was also retained (Cronbach's $\alpha=0.376$ ) since it is a unidimensional scale with small number of items [43, 48-50]. The corrected item-to-total correlation for most items in the different subscales were $>0.2$, which indicates that each item was correlated with the subscale it belongs to [43]. However, few items with item-to-total correlation $<0.2$ were retained when Cronbach's $\alpha$ did change if the item was deleted [44]. Inter-item correlations (data not shown) were also within the acceptable range of $<0.8$ [44]. Item analysis results of the five scales under study are shown in the Additional file 1.

\section{Test-retest reliability of the final questionnaire}

Results for the test-retest reliability are shown in Table 2. ICC was 0.778 for the knowledge scale, 0.921 for the attitude scale, 0.850 for the social norms scale, 0.848 for the self-efficacy scale, and 0.752 for the practices scale, indicating excellent consistency between the two sittings [46]. Inter-item correlation were statistically significant $(p<0.05)$ between the two sittings. The paired $t$ test analysis showed that the mean score did not vary significantly from $\mathrm{T} 1$ to $\mathrm{T} 2$.

\section{Discussion}

A questionnaire was developed to address the need for a valid and reliable tool to measure psychosocial determinants of eating behavior in Lebanon and the region. The questionnaire was constructed based on recently advocated healthy eating guidelines [31]. The food items used in the questionnaire were based on those most commonly consumed by the Lebanese population [51].

The scales for all the constructs measured in the questionnaire met the standard criteria for excellent content validity [35]. This indicates that each scale has an appropriate sample of items for the construct being measured [35]. The content validity ratio and content validity index for the scales studied were in accordance with those obtained for the Caspian-IV study questionnaire items assessing attitude and knowledge of the determinants of under- and overweight among Iranian children [52]. These results were in accordance as well with the finding of Koo et al. [53] in their study on the questionnaire developed to assess KAP toward whole grain among primary school children in Kuala Lumpur, Malaysia.

Construct validity was assessed by factor analysis. The results of factor analysis revealed good correlation between items; however, multidimensionality of the different scales was observed. The observed dimensions or subscales were in parallel with the content of the dietary guidelines examined. The knowledge scale measured awareness about energy and nutrient balance and knowledge of healthy nutrient sources and diet-disease associations. The practices scale measured the adherence to dietary guidelines, limiting unhealthy food choices and control of portion size. The attitude scale measured the judgment of the participants about limiting unhealthy food choices and the adherence to dietary guidelines. The self-efficacy scale measured their confidence in being able to follow a healthy lifestyle, choose healthy snacks, control calories, and follow dietary guidelines about breakfast consumption and fruit and vegetable intake. The social norms scale measured the existence of a role for important others in influencing healthy food choices.

Analysis of item-to-total correlation confirmed that each item belonged to its corresponding subscale. Further analysis of internal consistency using Cronbach's $\alpha$ revealed an acceptable level of internal consistency for the total scales and subscales identified from factor analysis for the knowledge, attitude, self-efficacy, and practices domains. Although certain subscales had moderate alpha values, Cronbach's alpha ranging between 0.5 and 
Table 2 Mean and standard deviations, Pearson's correlation coefficients, and intraclass correlation for the scores of each scale at T1 and T2 $(n=30)$

\begin{tabular}{|c|c|c|c|c|c|c|c|}
\hline \multirow[t]{3}{*}{ Scale } & \multicolumn{3}{|c|}{ Mean scores } & \multirow{3}{*}{$\begin{array}{l}\text { Correlation between } \\
\text { scores at } \mathrm{T} 1 \text { and } \mathrm{T} 2 \\
\text { Correlation coefficient }\end{array}$} & \multicolumn{3}{|c|}{ Intraclass correlation (ICC) } \\
\hline & $\mathrm{T} 1$ & $\mathrm{~T} 2$ & \multirow{2}{*}{$\begin{array}{l}\text { Paired } t \text { test } \\
p \text { value }\end{array}$} & & & & \\
\hline & \multicolumn{2}{|l|}{ Mean \pm SD } & & & ICC & $95 \% \mathrm{Cl}$ & Value \\
\hline Knowledge & $68.1 \pm 13.9$ & $67.2 \pm 15.2$ & $>0.05$ & $0.639^{*}$ & 0.778 & $0.527-0.896$ & $<0.001$ \\
\hline Attitude & $82.8 \pm 17.9$ & $83.3 \pm 21.0$ & $>0.05$ & $0.865^{*}$ & 0.921 & $0.830-0.964$ & $<0.001$ \\
\hline Social norms & $24.7 \pm 4.5$ & $24.8 \pm 6.1$ & $>0.05$ & $0.772^{*}$ & 0.850 & $0.680-0.930$ & $<0.001$ \\
\hline Self-efficacy & $41.6 \pm 7.9$ & $40.7 \pm 9.2$ & $>0.05$ & $0.744^{*}$ & 0.848 & $0.676-0.929$ & $<0.001$ \\
\hline Practices & $58.3 \pm 11.9$ & $57.0 \pm 9.6$ & $>0.05$ & $0.617^{*}$ & 0.752 & $0.472-0.884$ & $<0.001$ \\
\hline
\end{tabular}

* The correlations are significant at $P<0.05$

0.8 have been reported in the literature [54-57]. Furthermore, values of Cronbach's alpha less than 0.7 are common for one-dimensional scales with less than 10 items $[42,48]$ and have been justified. Loewenthal and Cortina justified that the alpha coefficient can be lower if the scale had fewer than 10 items due to the profound effect a small number of items have on the alpha value [42, 49]. Also, the low Cronbach's $\alpha$ of some subscales could be attributed to the difference in dispersion of the responses to items in the subscales. The tendency of individuals to answer toward the extremes will decrease the spread of responses on each subscale item, thus decreasing the size of sub-item correlations, consequently giving a lower Cronbach's $\alpha[58,59]$. Regarding the social norms scale, the construct has been studied and declared by several health behavior theories as an important predictor of behavior intention and health behavior [60]. Thus, for the sake of content validity and with the presence of the justified theoretical and practical reasoning described above, the items for the social norms scale were retained [42, 49, 60]. Furthermore, the moderate Cronbach's $\alpha$ for items in each scale or subscale indicate that items were satisfactorily interrelated with little redundancy [61]; thus, each item in each scale would be measuring something different. The low inter-item correlation observed would further indicate lower homogeneity which is preferable particularly for the use with areas of motivation and personality which is the case for this questionnaire [61].

In terms of temporal stability, the scores for all the retained items in the different scales and subscales showed good to excellent stability measured by ICC [46]. The results for the temporal stability of the current scales were in line with the reliability results of the "child nutrition questionnaire" [62], the SCREEN nutrition tool [63], and the ENERGY-child questionnaire [64]. Pearson correlation analysis confirmed the ICC results and were in accordance with those reported for the "school-based nutrition monitoring questionnaire" [65], the "nutrition knowledge questionnaire for obese adults" [66] the "questionnaire to test knowledge and practices of dietitians regarding dietary supplements" [67], the "physical activity questionnaire developed for parents of preschool children in Mexico" [68], and the "questionnaire on dietary fiber-related knowledge" [69].

\section{Conclusions}

The current research study provides the first psychometrically valid and reliable tool for use to assess psychosocial determinants of eating behavior among Lebaneseand Arabic-speaking adolescents in situation analysis. The results from the current study indicate that the scales developed are valid and reliable to measure the corresponding constructs constantly over time. The tool also included items that were satisfactorily interrelated, within each scale or subscale, as measured by Cronbach's $\alpha$ statistic, with little redundancy. The tool can measure the type and level of an adolescent's nutritional knowledge as well as their attitude toward healthy eating. Further, it can measure the strength of self-efficacy to abide by healthy eating practices and their current adherence to these practices and the influence of important others on their food choices.

Also, it can serve as a potential instrument for pretest and impact evaluation of ongoing nutrition education interventions and curricula. Based on results obtained, efficacious modifications can be instilled in nutrition policies or ongoing interventions to coin a nutrition-literate citizen, where nutrition literacy encompasses the cognitive and social skills, as well as the ability to gain access to, understand, and use nutrition information and material in ways which promote and maintain good health $[70,71]$. Hence, with monitoring and refining nutrition education, children will develop into productive members of society and contribute to national development [72].

\section{Additional file}

Additional file 1: Table S1. Rotated factor loading matrix, Item-to-total score correlation and internal consistency for the Knowledge scale items. (DOCX 33 kb) 


\section{Abbreviations}

CVR: Content validity ratio; ICC: Intraclass correlation; KMO test: Keiser-MeyerOlkin test; S-CVI: Scale content validity index; SME: Subject matter experts

\section{Acknowledgements}

Not applicable

\section{Funding}

Not applicable.

\section{Availability of data and materials}

Please contact the corresponding author for data requests.

\section{Authors' contributions}

$\mathrm{LI}$ designed the research, developed the questionnaire, collected the data, and performed the statistical analysis; HC and FS participated in the design, the development of the questionnaire, and the data collection and data analysis and critically reviewed the work and this report; and HD participated in the design and critically reviewed the statistical analysis and the work of this report. All authors read and approved the final manuscript.

\section{Authors' information}

Dr. Fikrat El Sahn is a professor of Nutrition at the High Institute of Public Health, Nutrition Department, Alexandria University.

Dr. Hanadi Chatila is an Assistant Professor of Science Education at the Faculty of Education, Department of Science Education, Lebanese University Dr. Hani Dimassi is an Associate Professor of Biostatistics at the School of Pharmacy, Lebanese American University

Leila Itani is a lecturer in Nutrition at the Faculty of Health Sciences, Department of Nutrition and Dietetics, Beirut Arab University

\section{Competing interests}

The authors declare that they have no competing interests.

\section{Ethics approval and consent to participate}

The study was part of an initiative to revise the national nutrition education curriculum. The participants were Lebanese public high school students mainly those in grade 12. For this reason, we sought the approval of the Ministry of Education and Higher Education in Lebanon in order to administer the questionnaire in schools. Before participation, students learned about the objectives and protocol of the study and were informed that their participation is completely voluntary. In addition, it was clearly explained to them that refusing participation will not affect their academic status. No compensation was offered to the students in return for their participation, and their verbal assent was obtained. Only those students who agreed to participate in the survey filled the questionnaire. The questionnaire was anonymous, and the data was only used for the purpose of the study.

\section{Publisher's Note}

Springer Nature remains neutral with regard to jurisdictional claims in published maps and institutional affiliations.

\section{Author details \\ ${ }^{1}$ Faculty of Health Sciences, Department of Nutrition and Dietetics, Beirut Literature, Humanities and Social Sciences, Lebanese University, Sin El Fil, Beirut, Lebanon. ${ }^{3}$ Faculty of Education, Department of Science Education, Institute of Public Health, Alexandria University, 65 St., Al-Horeya Road, Alexandria, Egypt. \\ Received: 22 November 2015 Accepted: 18 March 2017 Published online: 07 April 2017} Arab University, Riad El-Solh, Beirut 1107 2809, Lebanon. ${ }^{2}$ Doctoral School of Lebanese University, Furn El Shebback, Beirut, Lebanon. ${ }^{4}$ School of Pharmacy, Lebanese American University, Chouran, Beirut 1102 2801, Lebanon. ${ }^{5}$ High

\section{References}

1. Pollitt E. Does breakfast make a difference in school? J Am Diet Assoc. 1995; 95(10):1134-9.

2. Kelder SH, Perry CL, Klepp Kl, Lytle LL. Longitudinal tracking of adolescent smoking, physical activity, and food choice behaviors. Am J Public Health. 1994;84(7):1121-6
3. Committee on Adolescent Health Care Services and Models of Care for Treatment, Prevention and HD. Challenges in adolescent health care: workshop report. Washington, D.C.; 2007. Available from: http://www.nap. edu/catalog/12031.html. Accessed June 2015.

4. Shepherd J, Harden A, Rees R, Brunton G, Garcia J, Oliver S, et al. Young people and healthy eating: a systematic review of research on barriers and facilitators. Health Educ Res. 2006;21:239-57.

5. Demirozu BE, Pehlivan A, Camliguney AF. Nutrition knowledge and behaviours of children aged 8-12 who attend sport schools. Procedia - Soc Behav Sci. 2012;46:4713-7. Available from: http://linkinghub.elsevier.com/ retrieve/pii/S1877042812020605.

6. Contento IR. Nutrition education linking research, theory, and practice. Canada: Jones \& Bartlett Learning; 2007.

7. Bonaccio M, Di Castelnuovo A, Costanzo S, De Lucia F, Olivieri M, Donati $\mathrm{MB}$, et al. Nutrition knowledge is associated with higher adherence to Mediterranean diet and lower prevalence of obesity. Results from the Moli-sani study. Appetite. 2013;68:139-46. Available from: http://www.sciencedirect.com/science/article/pii/ S0195666313001657.

8. Wardle J, Parmenter K, Waller J. Nutrition knowledge and food intake. Appetite. 34(3):269-75. http://www.ncbi.n/m.nih.gov/pubmed/10888290.

9. Fitzgerald N, Damio G, Segura-Pérez S, Pérez-Escamilla R. Nutrition knowledge, food label use, and food intake patterns among Latinas with and without type 2 diabetes. J Am Diet Assoc. 2008;108:960-7.

10. Sahingoz SA, Sanlier N. Compliance with Mediterranean Diet Quality Index (KIDMED) and nutrition knowledge levels in adolescents. A case study from Turkey. Appetite. 2011;57:272-7. http://www.ncbi.nlm.nih.gov/pubmed/ 21624407.

11. Jun J, Kang J, Arendt SW. The effects of health value on healthful food selection intention at restaurants: considering the role of attitudes toward taste and healthfulness of healthful foods. Int J Hosp Manag. 2014;42:85-91. Elsevier Ltd; http://linkinghub.elsevier.com/retrieve/pii/S027843191400098X.

12. Berg C. Influences on Swedish schoolchildren's dietary selection: focus on fat and fibre at breakfast. Scand J Nutr. 2002:46:194-6.

13. Contento IR, Koch PA, Lee $H$. Adolescents demonstrate improvement in obesity risk behaviors after completion of choice, control, and change, a curriculum addressing personal agency and autonomous motivation. YJADA. 2010;110:1830-9. http://dx.doi.org/10.1016/j.jada.2010.09.015.

14. Pirzadeh A, Hazavei MM, Entezari MH, Hasanzadeh A. The effect of educational intervention on girl's behavior regarding nutrition: applying the beliefs, attitudes, subjective norms, and enabling factors. J Educ Health Promot. 2014;3:79. http://www.pubmedcentral.nih.gov/articlerender. fcgi?artid $=4165120 \&$ tool=pmcentrez\&rendertype=abstrac.

15. Wang D, Stewart D. The implementation and effectiveness of school-based nutrition promotion programmes using a health-promoting schools approach: a systematic review. Public Health Nutr. 2013;16:1082-100. http://www.ncbi.nlm.nih.gov/pubmed/22850118.

16. Avery A, Bostock L, McCullough F. A systematic review investigating interventions that can help reduce consumption of sugar-sweetened beverages in children leading to changes in body fatness. J Hum Nutr Diet. 2015;28(Suppl 1):52-64. http://www.ncbi.nlm.nih.gov/pubmed/25233843.

17. World Health Organization. Report of the brainstorming meeting on the development of a framework on the Nutrition-Friendly Schools Initiative. 2006. p. 6. Available from: http://www.who.int/nutrition/publications/ Montreux_Meeting Report.pdf.

18. World Health Organization. Technical paper: Regional strategy on nutrition 2010-2019. Regional committee for the Easter Mediterranean, Regional office for the Eastern Mditerranean. September 2010. EM/RC57/4.

19. Musaiger $A O$, Hassan AS, Obeid $O$. The paradox of nutrition-related diseases in the Arab countries: the need for action. Int J Environ Res Public Heal. 2011:8:3637-71.

20. Musaiger AO, Bader Z, Al-Roomi K, D'Souza R. Dietary and lifestyle habits amongst adolescents in Bahrain. Food Nutr Res. 2011;55:7122.

21. Naja F, Nasreddine L, Itani L, Chamieh MC, Adra N, Sibai AM, et al. Dietary patterns and their association with obesity and sociodemographic factors in a national sample of Lebanese adults. Public Health Nutr. 2011;14:1570-8. Available from: http://journals. cambridge.org/action/displayAbstract?fromPage=online $\&$ aid $=$ 8347238\nhttp://journals.cambridge.org/action/displayFulltext?type= 1\&fid=8347240\&jid=PHN\&volumeld=14\&issueld=09\&aid = 8347238\&bodyld=\&membershipNumber=\&societyETOCSession $=$ 
22. Naja F, Nasreddine L, Itani L, Adra N, Sibai a M, Hwalla N. Association between dietary patterns and the risk of metabolic syndrome among Lebanese adults. Eur J Nutr. 2013;52:97-105. http://www.pubmedcentral.nih. gov/articlerender.fcgi?artid=3549407\&tool=pmcentrez\&rendertype=abstract.

23. Nasreddine L, Naja F, Akl C, Chamieh MC, Karam S, Sibai AM, et al. Dietary, lifestyle and socio-economic correlates of overweight, obesity and central adiposity in Lebanese children and adolescents. Nutrients. 2014;6:1038-62.

24. Nasreddine L, Naja F, Chamieh MC, Adra N, Sibai A-M, Hwalla N. Trends in overweight and obesity in Lebanon: evidence from two national cross-sectiona surveys (1997 and 2009). BMC Public Health. 2012;12:798. Available from: http:// bmcpublichealth.biomedcentral.com/articles/10.1186/1471-2458-12-798.

25. Badran M, Laher I. Obesity in Arabic-speaking countries. J Obes. 2011;2011: 686430. Available from: http://www.pubmedcentral.nih.gov/articlerender. fcgi?artid=3228340\&tool=pmcentrez\&rendertype=abstract.

26. Naja F, Hwalla N, Itani L, Karam S, Mehio Sibai A, Nasreddine L. A Western dietary pattern is associated with overweight and obesity in a national sample of Lebanese adolescents (13-19 years): a cross-sectional study. Br J Nutr. 2015;1-11. Available from: http://www.journals.cambridge.org/ abstract_S0007114515003657.

27. Aounallah-Skhiri H, Traissac P, El Ati J, Eymard-Duvernay S, Landais E, Achour N, et al. Nutrition transition among adolescents of a south-Mediterranean country: dietary patterns, association with socio-economic factors, overweight and blood pressure. A cross-sectional study in Tunisia. Nutr J. 2011;10:38.

28. Musaiger AO. Overweight and obesity in Eastern Mediterranean Region: prevalence and possible causes. J Obes. 2011;2011:407237. Available from: http://www.pubmedcentral.nih.gov/articlerender.fcgi?artid=3175401\&tool= pmcentrez\&rendertype=abstract.

29. Food and Agricultural Organization. Nutrition education in primary school. A guide for curriculum development. Vol1. The Reader. Rome, Italy; 2005.

30. USDA. Dietary guidelines for Americans, 2010. 7th ed. Washington: Government Printing Office; 2010

31. National Health and Medical Research Council. Australian Dietary Guidelines. Canberra: National Health and Medical Research Council, Canberra; 2013. Available from: https://www.nhmrc.gov.au/_files_nhmrc/file/publications/ n55_australian_dietary_guidelines1.pdf.

32. Hwalla N, Nasreddine LF-JS. The food-based dietary guideline manual for promoting healthy eating in the Lebanese adult population. 2012.

33. Lawshe C. A quantitative approach to content validity 1. Pers Psychol. 1975: 563-75. Available from: http://www.blackwell-synergy.com/doi/abs/10.1111/ j.1744-6570.1975.tb01393.x.

34. Ayre C, Scally AJ. Critical values for Lawshe's content validity ratio: revisiting the original methods of calculation. Meas Eval Couns Dev (Sage Publ Inc). 2014:47:79-86. Available from: 10.1177/0748175613513808\nhttp://off campus.lib.washington.edu/login?url=http://search.ebscohost.com/login. aspx?direct=true \&db=a9h\&AN=92969452\&site=ehost-live.

35. Polit DF, Beck CT. The content validity index: are you sure you know what's being reported? Critique and recommendations. Res Nurs Health. 2006;29: 489-97.

36. DeVon $\mathrm{H}$ a, Block ME, Moyle-Wright P, Ernst DM, Hayden SJ, Lazzara DJ, et al. A psychometric toolbox for testing validity and reliability [electronic version]. J Nurs Scholarsh. 2007;39:155-64.

37. Pett MA, Lackey NR, Sullivan JJ. Making sense of factor analysis: the use of factor analysis for instrument development in health care research. Thousand Oaks: Sage Pub; 2003.

38. Parmenter K, Wardle J. Evaluation and design of nutrition knowledge measures. J Nutr Educ. 2000;32:269-77. Available from: http://www.jneb.org/ article/S0022-3182(00)70575-9/abstract.

39. Tavakol M, Dennick R. Making sense of Cronbach's alpha. Int J Med Educ. 2011:2:53-5.

40. Bland JM, Altman DG. Statistics notes. Cronbach's alpha. BMJ. 1997:314:572.

41. Bowling A. Research methods in health. Investigating health and health services. 2nd ed. Buckingham: Open University Press; 2002.

42. Cortina JM. What is coefficient alpha? An examination of theory and applications. J Appl Psychol. 1993;78:98-104.

43. Kline P. A handbook of test construction. London: Routledge; 1993.

44. Nunnally J, Bernstein I. Psychometric theory, 3rd edn. New York: McGrawHill; 1994

45. Weir JP. Quantifying test-retest reliability using the intraclass correlation coefficient and the SEM. J Strength Cond Res. 2005;19:231-40. Available from: http://journals.lww.com/nscajscr/abstract/2005/02000/quantifying test_retest_reliability_using_the.38.aspx.
46. Fleiss J. The design and analysis of clinical experiments. New York: Wiley; 1986.

47. Sočan G. Scoring of multiple choice items by means of internal linear weighting. Rev Psychol. 2009;16:77-85.

48. Sijtsma K. On the use, the misuse, and the very limited usefulness of Cronbach's alpha. Psychometrika. 2009;74:107-20.

49. Loewenthal K. An introduction to psychological tests and scales. 2nd ed. Philadelphia: Psychology Press; 2001.

50. Parmenter K, Wardle J. Development of a general nutrition knowledge questionnaire for adults. Eur J Clin Nutr. 1999;53:298-308.

51. Nasreddine L, Hwalla N, Sibai A, Hamzé M, Parent-Massin D. Food consumption patterns in an adult urban population in Beirut, Lebanon. Public Health Nutr. 2006;9:194-203.

52. Kelishadi R, Majdzadeh R, Motlagh M-E, Heshmat R, Aminaee T, Ardalan G, et al. Development and evaluation of a questionnaire for assessment of determinants of weight disorders among children and adolescents: the CASPIAN IV study. Int J Prev Med. 2012;3:699-705. Available from: http://www.pubmedcentral.nih.gov/articlerender.fcgi?artid=3482997\&tool= pmcentrez\&rendertype=abstract.

53. Koo HC, Poh BK, Ruzita AT. Development, validity and reliability of a questionnaire on knowledge, attitude and practice (KAP) towards whole grain among primary school children in Kuala Lumpur, Malaysia. Int Food Res J. 2016;23:797-805

54. Anderson AS, Bell A, Adamson A, Moynihan P. A questionnaire assessment of nutrition knowledge - validity and reliability issues. Public Health Nutr. 2002:5:497-503

55. Sapp SG, Jensen HH. Reliability and validity of nutrition knowledge and diet-health awareness tests developed from the 1989-1991 Diet and Health Knowledge Surveys. J Nutr Educ. 1997;29:63-72. Available from: http://www. jneb.org/article/S0022-3182(97)70157-2/abstract.

56. Contento I. Review of nutrition education research in the Journal of Nutrition Education and Behavior, 1998 to 2007. J Nutr Educ Behav. 2008;40:331-40.

57. Obayashi S, Bianchi $\sqcup$, Song WO. Reliability and validity of nutrition knowledge, social-psychological factors, and food label use scales from the 1995 Diet and Health Knowledge Survey. J Nutr Educ Behav. 2003;35:83-92.

58. lacobucci D. Methodological and statistical concerns of the experimental behavioral researcher. J Consum Psychol. 2001;10:1-2.

59. Nunnally J, Bernstein I BJ. Psychometric theory. Vol. 226. New York: McGrawHill; 1967

60. Ajzen I. The theory of planned behavior. Organ Behav Hum Decis Process. 1991;50:179-211. Available from: http://www.sciencedirect.com/science/ article/pii/074959789190020T.

61. Panayides P. Coefficient alpha: interpret with caution. Eur J Psychol. 2013;9: 687-96. Available from: http://ejop.psychopen.eu/article/view/653/html. [cited 2016 Oct 8].

62. Wilson AM, Magarey AM, Mastersson N. Reliability and relative validity of a child nutrition questionnaire to simultaneously assess dietary patterns associated with positive energy balance and food behaviours, attitudes, knowledge and environments associated with healthy eating. Int J Behav Nutr Phys Act. 2008:5:5.

63. Keller HH, McKenzie JD, Goy RE. Construct validation and test-retest reliability of the seniors in the community: risk evaluation for eating and nutrition questionnaire. J Gerontol A Biol Sci Med Sci. 2001;56:M552-8.

64. Singh AS, Vik FN, Chinapaw MJ, Uijtdewilligen L, Verloigne M, Fernández-Alvira $J M$, et al. Test-retest reliability and construct validity of the ENERGY-child questionnaire on energy balance-related behaviours and their potential determinants: the ENERGY-project. Int J Behav Nutr Phys Act. 2011:136.

65. Penkilo M, George GC, Hoelscher DM. Reproducibility of the School-Based Nutrition Monitoring Questionnaire among fourth-grade students in Texas. J Nutr Educ Behav. 2008:40:20-7.

66. Feren A, Torheim LE, Lillegaard ITL. Development of a nutrition knowledge questionnaire for obese adults. Food Nutr Res. 2011:55:1-7. Available from: http://www.pubmedcentral.nih.gov/articlerender.fcgi?artid=3193827\&tool= pmcentrez\&rendertype=abstract.

67. Steyn NP, Labadarios D, Nel JH, Heidi-Lee R. Development and validation of a questionnaire to test knowledge and practices of dietitians regarding dietary supplements. Nutrition. 2005:21:51-8.

68. Bacardi-Gascon M, Reveles-Rojas C, Woodward-Lopez G, Crawford P, Jimenez-Cruz A. Assessing the validity of a physical. J Heal Popul Nutr. 2012;30:439-46. Available from: https://www2.scopus.com/inward/record. uri?eid=2-s2.0-84873125876\&partner $\mid \mathrm{D}=40 \&$ md5 $=54$ ea 8962490 e 827 a52a 11 ce92e39f590 
69. Deniz MS, Alsaffar AA. Assessing the validity and reliability of a questionnaire on dietary fibre-related knowledge in a Turkish student population. J Heal Popul Nutr. 2013;31:497-503.

70. Nutbeam D. Health promotion glossary. Health Promot. 1986;1:113-27.

71. Silk KJ, Sherry J, Winn B, Keesecker N, Horodynski MA, Sayir A. Increasing nutrition literacy: testing the effectiveness of print, web site, and game modalities. J Nutr Educ Behav. 2008;40:3-10.

72. UNICEF. Global life skills education evaluation. Draft final report. London: United Kingdom Education for Change Ltd; 2012.

Submit your next manuscript to BioMed Central and we will help you at every step:

- We accept pre-submission inquiries

- Our selector tool helps you to find the most relevant journal

- We provide round the clock customer support

- Convenient online submission

- Thorough peer review

- Inclusion in PubMed and all major indexing services

- Maximum visibility for your research

Submit your manuscript at www.biomedcentral.com/submit 